\title{
The type 2C phosphatase Wip1: An oncogenic regulator of tumor suppressor and DNA damage response pathways
}

\author{
Xiongbin Lu • Thuy-Ai Nguyen • Sung-Hwan Moon • \\ Yolanda Darlington • Matthias Sommer • \\ Lawrence A. Donehower
}

Published online: 12 February 2008

(C) The Author(s) 2008

\begin{abstract}
The Wild-type p53-induced phosphatase 1, Wip1 (or PPM1D), is unusual in that it is a serine/threonine phosphatase with oncogenic activity. A member of the type $2 \mathrm{C}$ phosphatases (PP2C $\delta$ ), Wip1 has been shown to be amplified and overexpressed in multiple human cancer types, including breast and ovarian carcinomas. In rodent primary fibroblast transformation assays, Wip1 cooperates with known oncogenes to induce transformed foci. The recent identification of target proteins that are dephosphorylated by Wip1 has provided mechanistic insights into its oncogenic functions. Wip1 acts as a homeostatic regulator of the DNA damage response by dephosphorylating proteins that are substrates of both ATM and ATR, important DNA damage sensor kinases. Wip1 also suppresses the activity of multiple tumor suppressors, including $\mathrm{p} 53$, ATM, p16 $6^{\mathrm{INK} 4 \mathrm{a}}$ and ARF. We present evidence that the suppression of p53, p38 MAP kinase, and ATM/ATR signaling pathways by Wip1 are important components of
\end{abstract}

X. Lu $\cdot$ M. Sommer $\cdot$ L. A. Donehower $(\bowtie)$

Department of Molecular Virology and Microbiology,

Baylor College of Medicine,

Houston, TX 77030, USA

e-mail: larryd@bcm.tmc.edu

T.-A. Nguyen · Y. Darlington • L. A. Donehower Interdepartmental Graduate Program in Cell and Molecular Biology, Baylor College of Medicine,

Houston, TX 77030, USA

S.-H. Moon • L. A. Donehower

Department of Molecular and Cellular Biology,

Baylor College of Medicine,

Houston, TX 77030, USA

X. Lu

Department of Biological Sciences, University of South Carolina,

Columbia, SC 29208, USA its oncogenicity when it is amplified and overexpressed in human cancers.

Keywords Wip1 PPM1D - Serine/threonine phosphatase · PP2C $\cdot \mathrm{p} 53 \cdot$ ATM

$\begin{array}{ll}\text { Abbreviations } \\ \text { ARF } & \text { alternate reading frame of the ink4a locus } \\ \text { ATM } & \text { ataxia telangiectasia mutated } \\ \text { ATR } & \text { ataxia telangiectasia and Rad3-related } \\ \text { BER } & \text { base excision repair } \\ \text { BRCA1 } & \text { breast cancer gene 1 } \\ \text { Chk1 and 2 } & \text { checkpoint kinases 1 and 2 } \\ \text { DNA-PK } & \text { DNA-dependent protein kinase } \\ \text { MAPK } & \text { mitogen-activated protein kinase } \\ \text { MEF } & \text { mouse embryo fibroblast } \\ \text { Mdm2 } & \text { mouse double minute 2 } \\ \text { MKK6 } & \text { MAPK kinase 6 } \\ \text { MMTV } & \text { mouse mammary tumour virus } \\ \text { PIKK } & \text { phosphoinositide-3-kinase-related kinase } \\ \text { PP2C } & \text { protein phosphatase type 2C } \\ \text { RB } & \text { retinoblastoma } \\ \text { UNG2 } & \text { uracil DNA glycosylase 2 } \\ \text { Wip1 } & \text { wild-type p53-induced phosphatase 1 } \\ \text { Wnt } & \text { wingless/INT }\end{array}$

\section{Introduction}

Cellular DNA is constantly exposed to various environmental and endogenous mutagenic insults. To maintain genomic integrity and prevent cancer in the face of these potentially mutagenic events, cells have evolved a sophisticated array of damage sensors, signaling molecules, and repair functions. Among the key sensors of DNA damage are 
the phosphoinositide-3-kinase-related kinase (PIKK) family, that include ATM (ataxia-telangiectasia $m$ utated), ATR (ataxia-telangiectasia and Rad3-related), and DNA-PK (DNA dependent protein kinase catalytic subunit) $[1,2]$. Most PIKKs are serine/threonine kinases that are conserved from yeast to humans and phosphorylate key target proteins in various DNA damage response pathways $[3,4]$. The direct importance of the ATM/ATR-initiated damage response pathways in cancer prevention has recently been demonstrated by two groups [5, 6]. Human pre-neoplastic lesions from a variety of different human cancers were shown to express markers of an activated DNA damage response, including activated and phosphorylated ATM, Chk2, p53, and $\mathrm{H} 2 \mathrm{AX}[5,6]$. Interestingly, late stage tumors often showed loss of these DNA damage response markers, suggesting that the disabling of DNA damage response pathways is an important prerequisite for cancer progression $[5,6]$.

In studies of the DNA damage response, most attention has been focused on the activation and execution of that response. Less attention has been given to the reversal of the response. Once cell division has been halted and the DNA damage has been repaired, how does the cell return to its normal pre-stress state and re-enter cell division? Since activation of the damage response often occurs through phosphorylation of key downstream targets of ATM/ATR, phosphatases are obvious candidates as homeostatic regulators of the DNA damage response. In this review we will discuss the evidence that the Wild-type p53-induced phosphatase 1 , or Wip1, is a major homeostatic regulator of the ATM/ATR-initiated DNA damage response.

In addition to its homeostatic role in the DNA damage response, we will also describe how Wip1 downregulates important tumor suppressor molecules. Wip1 has been shown to inhibit $\mathrm{p} 53$ by multiple mechanisms and to downregulate p38 MAP kinase through dephosphorylation [5, 7-11]. Expression of $\mathrm{p} 16^{\mathrm{INK} 4 \mathrm{a}}$ and $\mathrm{p} 14^{\mathrm{ARF}}$ have also been shown to be suppressed in some contexts by Wip1 [12]. The inhibition of these tumor suppressors is likely to be a major component of the oncogenic activity of this phosphatase.

\section{Discovery and initial characterization of Wip1}

Appella and colleagues originally identified the human Wip1 gene by screening for genes induced in a p53dependent manner in response to ionizing radiation (IR) in WMN Burkitt lymphoma cells [13]. Using mRNA differential display methodology, they identified a novel p53induced gene. The Wipl transcript was induced by ultraviolet (UV) and IR in a p53-dependent manner [13]. Tumor cell lines with wild-type p53 consistently showed IR-induced increases in Wip1 mRNA while p53-deficient cell lines showed little or no induction of Wip1 expression following radiation treatment. Cellular fractionation and indirect immunofluorescence indicated that the $61 \mathrm{kDa}$ Wip1 protein localizes to the nucleus [13].

The 605 amino acid human Wip1 protein sequence can be subdivided into two major domains, a highly conserved $\mathrm{N}$-terminal phosphatase domain from amino acids 1-375, and a less conserved non-catalytic domain extending from amino acids 376-605. This C-terminal domain of Wip1 may facilitate nuclear localization. However, although this domain contains two putative nuclear localization signals, mutation of these motifs failed to prevent nuclear localization [14]. In addition, the C-terminal domain shows high conservation among mammalian Wipls and limited conservation with non-mammalian Wip1 molecules, but little or no similarity with other phosphatases (Fig. 1). The phosphatase domain of Wip1 shows the highest levels of similarity to the type $2 \mathrm{C}$ family of serine/threonine protein phosphatases (PP2C), consistent with its observed biochemical activities (Fig. 1(b)) [13, 15].

Using the human Wipl cDNA as a probe, our laboratory isolated the murine Wip1 gene and mapped it to mouse chromosome 11 [16]. The human Wipl gene is located on chromosome 17q22/q23 [17]. The murine Wip1 protein contains 598 amino acids and migrates at approximately $66 \mathrm{kDa}$ on a SDS-PAGE gel [16]. The murine and human Wip1 protein sequences have an overall identity of $83 \%$ and an overall similarity of $86 \%$. RT-PCR and Northern blot analyses revealed that the Wipl mRNA is ubiquitously expressed in all mouse embryonic and adult tissues, with a very high level of expression in the testis. Wipl mRNA levels fluctuate during development [16].

\section{Wip1 is a type 2C phosphatase}

Wip1 is a member of the magnesium-dependent serine/ threonine protein phosphatase (PPM) family $[18,19]$. This is a large and varied family of protein phosphatases present in both prokaryotes and eukaryotes, whose defining member is PP2C $\alpha$ [20, 21]. To date, 18 human PPM/ PP2C genes have been identified [19]. In prokaryotes and eukaryotes, the PPM/PP2C family of phosphatases plays a role in regulating stress response pathways $[18,20,21]$.

Like other PPM/PP2C family members, Wip1 is a monomeric enzyme that requires divalent cations, mainly $\mathrm{Mg}^{2+}$ or $\mathrm{Mn}^{2+}$, for catalytic efficacy and is insensitive to okadaic acid, a potent inhibitor of the PP1 and PP2A phosphatases $[18,20,21]$. Using a BLAST search of the sequence database, human Wip1 shows an overall identity of $30 \%$ and an overall similarity of $45 \%$ to human PP2C $\alpha$ and PP2C $\beta$ (Fig. 1(b)). Like PP2C $\alpha$ and PP2C $\beta$, Wip1 also negatively regulates the stress responsive p38 mitogen- 
(a)

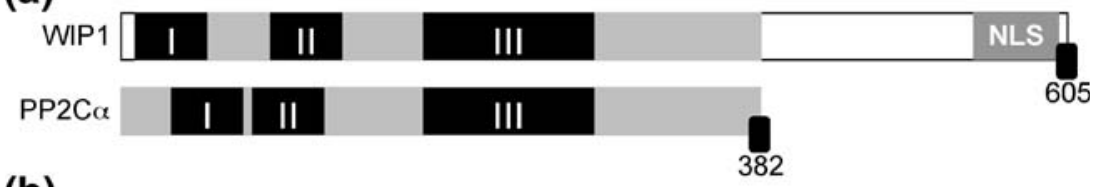

(b)

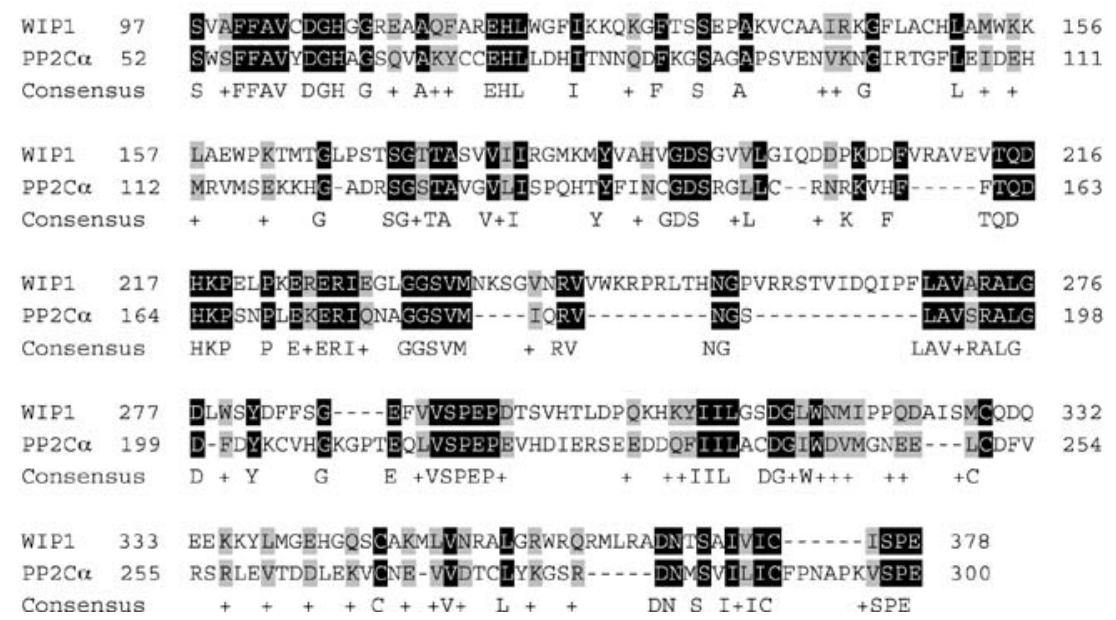

Fig. 1 Protein sequence alignment of human Wip1 and human $\mathrm{PP} 2 \mathrm{C} \alpha$. (a) The overall structures of Wip1 (top) and PP2C $\alpha$ (bottom) show significant similarity. The conserved type $2 \mathrm{C}$ phosphatase domain is shaded in Wip1. The regions of more highly conserved sequences labeled I, II, and III are shown as black blocks. The Cterminal non-catalytic domain that is present only in Wip1 molecules (and is also well conserved among mammalian Wip1 orthologues) is

indicated by the white block. A putative nuclear localization signal (NLS) is also indicated near the C-terminus of Wip1. (b) Primary amino acid sequence alignment between human Wip1 and human PP2C $\alpha$ phosphatase domains is shown. Identical amino acids are highlighted with a black background while conservative amino acid substitutions are indicated with a gray background. The phosphatase domains of the two molecules show $30 \%$ identity and $45 \%$ similarity

activated protein kinase (MAPK) pathway by directly inactivating p38 through dephosphorylation of phosphothreonine 180 of the regulatory pTXpY motif found in the activation loop of the kinase [11, 22, 23].

Based on the sequence homology between Wip1 and $\mathrm{PP} 2 \mathrm{C} \alpha, \beta$, and $\gamma$, Yamaguchi et al. [15] developed a structural model for the catalytic domain of Wip1. From these studies, Arg76 of human Wip1 (Arg69 of mouse Wip1) aligned with $\operatorname{Arg} 33$ of $\mathrm{PP} 2 \mathrm{C} \alpha$, suggesting that Arg76 of human Wip1 performs the same role as the catalytic Arg33 of PP2C $\alpha$. Substrate specificity studies indicated that peptides containing pSXpY inhibit Wip1, while pTXpY peptides are Wip1 substrates [24]. Sequences on either side of the pTXpY motif did not greatly affect Wip1 activity, but the residue (X) lying between the two conserved phospho-acceptors affected Wip1 affinity and correlated with selectivity for MAP kinases. From these studies a specific Wip1 inhibitor was developed, and using simulations with the proposed structural model of Wip1, the phospho-Ser of the inhibitor was shown to be in contact with the proposed catalytic Arg76, thus blocking its interaction with potential targets [24].

While the specificity of Wip1 for pTXpY motifs is clear from biochemical and cell biology studies [11, 15, 24, 25], the recent identification of targets in which Wip1 dephos- phorylates sites modified by ATM/ATR indicates an additional specificity. ATM and ATR phosphorylate $\mathrm{pS} /$ pTQ sites in over 700 proteins in the cell [4] and Wip1 has been shown to dephosphorylate $\mathrm{pS} / \mathrm{pTQ}$ sites in vitro and in vivo on at least five proteins, ATM, Chk1, Chk2, p53, and Mdm2 (see Fig. 2) [7-9, 26].

\section{Identification of Wip1 targets reveals it to be a homeostatic regulator of the DNA damage response}

4.1 Wip1 dephosphorylates DNA damage response/repair proteins at TXY motifs

Once Wip1 was shown to be a serine/threonine phosphatase, it was clear that its functional roles might best be understood by identifying Wip1 target proteins and dephosphorylation sites. Since the discovery of Wip1, at least seven Wip1 dephosphorylation targets have been definitively identified. These are listed in Table 1 . Note that on the seven target proteins, two distinct motifs appear to be dephosphorylated by Wip1, pTXpY and pS/pTQ. One key commonality is their importance in the cellular DNA damage/repair response. Wip1 acts as an inhibitor or 


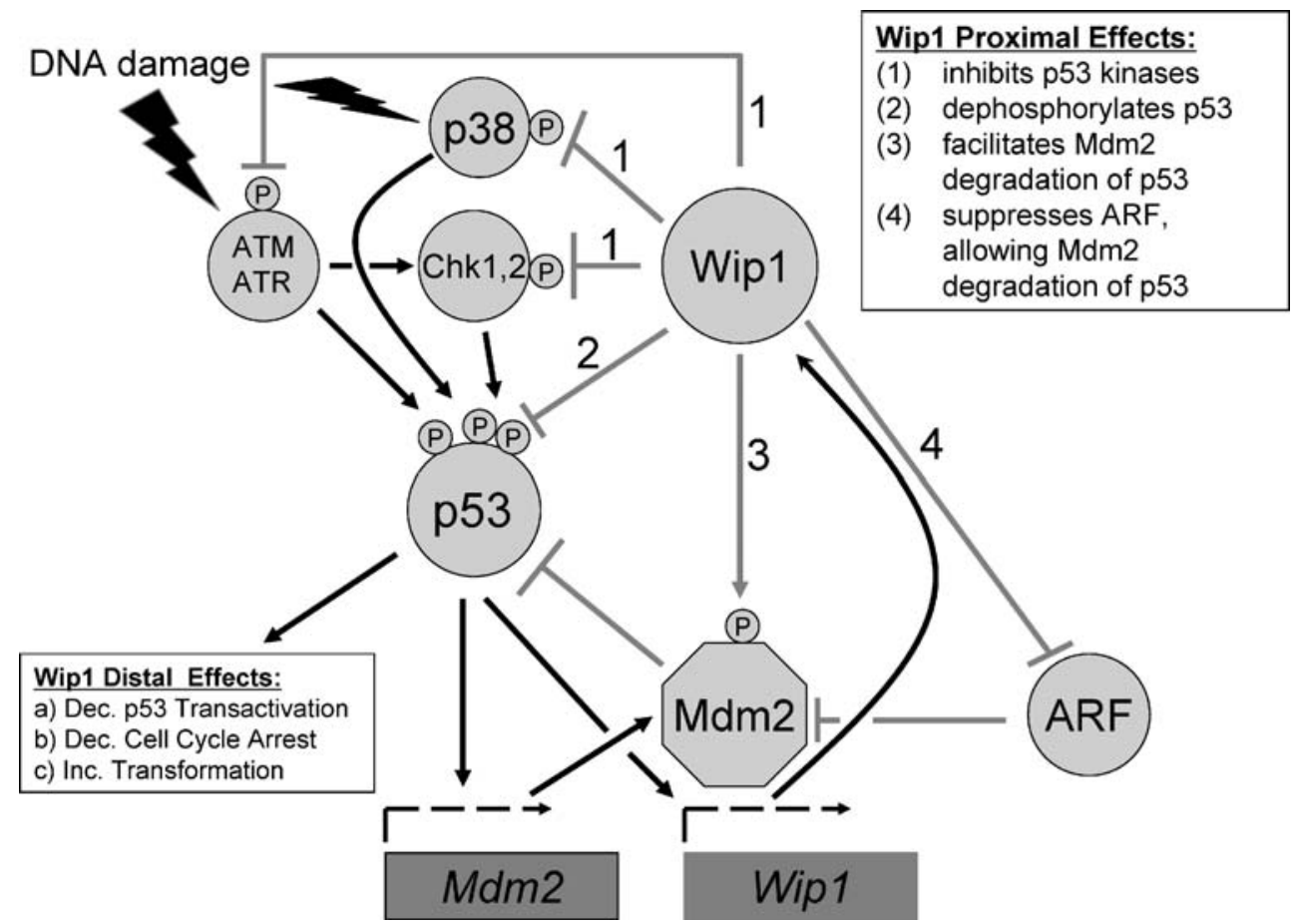

Fig. 2 Wip1 inhibits p53 activity by multiple mechanisms. When a cell is stressed by DNA damage, ATM, ATR, and p38 MAP kinase can phosphorylate $\mathrm{p} 53$ directly or through intermediary proteins such as Chk1 and Chk2. Phosphorylated p53 localizes to the nucleus and transactivates a battery of anti-proliferative genes. In addition, two p53 autoregulatory genes are activated, Mdm2 and Wip1. Mdm2 is an E3 ubiquitin ligase that promotes p53 degradation. However, early after the DNA damage response ATM (and possibly ATR) phosphorylate Mdm2 and this promotes Mdm2 degradation and prevents Mdm2 mediated p53 degradation. Activated p53 also upregulates Wip1 expression and after DNA damage is repaired, the accumulated Wip 1 phosphatase inhibits a battery of proteins that activate $\mathrm{p} 53$. Wip 1 dephosphorylates the upstream kinases that phosphorylate p53 (ATM,

homeostatic regulator of the DNA damage response, facilitating the return of the cell to a normal pre-stress state following repair of the DNA damage. As indicated in Table 1, five of the seven identified dephosphorylation targets are phosphorylated by the PIKKs ATM and ATR, which are key sensor proteins that activate numerous components of the p38, Chk1, Chk2) and p53 itself (at Ser15). In addition, Wip1 dephosphorylates $\mathrm{Mdm} 2$ at Ser395 and this results in Mdm2 stabilization and Mdm2 mediated p53 degradation. Finally, increased Wip1 levels suppresses ARF which in turn results in increased Mdm2 activity and $\mathrm{p} 53$ proteolysis. The resulting destabilization of $\mathrm{p} 53$ helps return the normal cell to a pre-stress state after cellular damage is repaired. However, if Wipl becomes amplified or overexpressed during tumor cell progression, this could result in chronic suppression of p53 activity and promote tumorigenesis. In the figure, proteins are indicated by circles or octagons and genes are indicated by rectangles. Small circles marked with P indicate phosphorylation sites. Black lines indicate early events in the DNA damage response and gray lines show later homeostatic events in the damage response

DNA damage response pathways in the cell. We hypothesize that Wip1 serves as a major off switch for the ATM/ ATR-initiated DNA damage signaling cascade $[7,26]$. Note also that six of the seven Wip1 targets are important regulators of p53 function. The four kinases p38, Chk1, Chk2, and ATM all phosphorylate p53 and promote its

Table 1 Identified Wip1 dephosphorylation targets

\begin{tabular}{llllllll}
\hline Protein & Site $^{\text {a }}$ & Motif & Kinase & Protein function & Wip1 effects & p53 effect? & Reference \\
\hline p38 MAPK & T180 & TXY & MKK3/6 & Stress response & Dec. kinase activity & Yes (dec.) & Takekawa et al. [11] \\
UNG2 & T6 & TXY & ? & Base excision repair & Dec. uracil excision & No & Lu et al. [25] \\
Chk1 & S345 & S/TQ & ATR & DNA damage response & Dec. kinase activity & Yes (dec.) & Lu et al. [10] \\
p53 & S15 & S/TQ & ATM & DNA damage response & Dec. apoptosis & Yes (dec.) & Lu et al. [10] \\
Chk2 & T68 & S/T/Q & ATM & DNA damage response & Dec. kinase activity & Yes (dec.) & Fujimoto et al. [9] \\
ATM & S1981 & S/TQ & ATM & DNA damage response & Dec. kinase activity & Yes (dec.) & Shreeram et al. [7] \\
Mdm2 & S395 & S/TQ & ATM & p53 regulation & Dec. p53 levels & Yes (dec.) & Lu et al. [8] \\
\hline
\end{tabular}

${ }^{a}$ Listed sites are from the human proteins; mouse sites (e.g. p53 S18 or ATM S1987) may be at different amino acid codons

${ }^{\mathrm{b}}$ Also sites Ser19, Ser33/35, Thr68, and Thr432

${ }^{\mathrm{c}}$ Activated ATM autophosphorylates itself at S1981; S367 also dephosphorylated by Wip1 
activation [27-30]. Wip1 dephosphorylation of these p53 kinases decreases their intrinsic activity. Dephosphorylation of p53 at serine 15 by Wip 1 also contributes to p53 degradation, as does dephosphorylation of $\mathrm{Mdm} 2$, which stabilizes Mdm2, an E3 ubiquitin ligase specific for p53 [31]. Thus, Wip1 appears to be a critical inhibitor of $p 53$ function and such effects are likely to play a major role in Wip1 oncogenicity (see below). In this section, we will describe the proteins, which have been identified as targets for dephosphorylation by Wip 1 and how Wip1 regulates the function(s) of these proteins.

\subsubsection{TXY motif: $p 38$}

The first identified target of Wip1 was the p38 mitogenactivated protein kinase (p38 MAP kinase) [11]. Genotoxic stress such as UV radiation causes activation of p38 MAP kinase by dual phosphorylation on Thr180 and Tyr182 [32, 33]. The phosphorylated $\mathrm{p} 38$, in turn, phosphorylates $\mathrm{p} 53$ on Ser15, Ser33, Ser46 and Ser392 and increases p53 activities, including gene transcription and apoptosis [28, 34, 35]. p38 was shown to interact with Wip1 and to be dephosphorylated by Wip1 on its Thr180 residue [11]. Wip1 dephosphorylation of p38 was associated with reduced nuclear localization of p38 and reduced kinase activity towards Ser33 and Ser46 of p53 [11]. Dephosphorylation of Ser33 and Ser46 on p53 was accompanied by reduced p53 transcriptional activation activity and reduced p53-mediated apoptotic function following UV irradiation. Thus, Wip1 inhibits UV-induced phosphorylation of p53 on Ser33 and Ser46 via p38 downregulation, functioning as a mediator in a p53 negative feedback regulatory loop.

\subsubsection{TXY motif: UNG2}

Uracil is a common DNA lesion formed by deamination of cytosine or misincorporation of dUMP, leading to transition mutations or generation of AP sites (apurinic/apyrimidinic sites) in the genome. Such lesions are repaired by base excision repair (BER) that is initiated by a uracil DNA glycosylase [36]. At least four different mammalian uracil DNA glycosylases have been identified. Of these, the nuclear UNG2 encoded by the $U N G$ gene is the major enzyme responsible for removing uracil and creating an apyrimidinic site for further repair processing [36].

To identify Wip 1 interacting proteins, our laboratory performed bacterial two-hybrid assays with Wip1 bait constructs and we repeatedly pulled down UNG2 as a major interactor. In vitro and in vivo interaction studies by us and global human interactome screens by others confirmed that UNG2 is a Wip1 interacting protein [25, 37]. Analysis of the UNG2 sequence revealed two TXY motifs at Thr6 and Thr126, which show similarities to the
Wip1 target site on p38 MAP kinase. We utilized UNG2 phosphothreonine 6 and 126 specific antibodies generated by the Appella laboratory to show that UV irradiation induced UNG2 phosphorylation at both Thr residues and that this enhances UNG2 enzymatic activity. Of these two target residues, only Thr6 was dephosphorylated by Wip1 in cells. Dephosphorylation of UNG2 by Wip1 resulted in reduced uracil-associated DNA incision activity, a critical step in BER [25]. Moreover, we were able to show that human cell lines overexpressing a Wip1 expression construct exhibited reduced global BER activity, while the same cells transfected with Wip1 siRNA exhibited enhanced global BER activity, indicating Wip1 inhibits base excision repair, in part by dephosphorylating UNG2 $[25,38]$.

4.2 Wip1 dephosphorylates DNA damage response proteins at $\mathrm{S} / \mathrm{TQ}$ motifs

\subsubsection{S/TQ motif: Chk1, Chk2}

The checkpoint kinases Chk1 and Chk2 are evolutionarily conserved kinases which play a crucial role in regulating DNA damage responses [39]. In response to DNA damage or replicative stress, Chk1 is phosphorylated on Ser317 and Ser345 mainly by the ATR kinase [40]. The phosphorylation on these two serine residues is a critical event for Chk1 activation in that mutants of Chk1 in which Ser317 and Ser345 residues were replaced with alanine showed poor kinase activity. Following activation, Chk1 phosphorylates and inactivates $\mathrm{Cdc} 25$ phosphatase family members to facilitate cell cycle arrest [41].

Chk2 activation is a multistep process initiated by phosphorylation on Thr68 mainly by ATM in response to DNA damage $[42,43]$. Although Thr68 phosphorylation is not the only requirement for full activation of Chk2, the T68A mutation significantly reduced Chk2 kinase activity [44]. Activated Chk2 targets a variety of proteins involved in cell cycle control, DNA repair and apoptosis, including p53, BRCA1, PML, E2F-1, and the Cdc25 phosphatase family. Notably, ATR-Chk1 and ATM-Chk2 pathways are not strictly separated but rather highly connected and coordinated as evidenced by ATM-dependent phosphorylation of Chk1 in response to ionizing radiation [45], ATMindependent activation of Chk2 [46], and ATR activation regulated by ATM $[47,48]$.

The identification of Chk1 as a Wip1 target followed coimmunoprecipitation experiments in our laboratory that showed that Wip1 consistently bound Chk1 in cells [10]. In vitro phosphatase assays showed that Wip1 dephosphorylated Chk1 at Ser345, but not Ser317. In vivo assays demonstrated that overexpressed Wip1 suppressed UVinduced phosphorylation of Chk1 Ser345 while Wip1 
siRNA enhanced Chk1 Ser345 phosphorylation compared to controls. Importantly, dephosphorylation of Chk1 at Ser345 resulted in reduced Chk1 kinase ability on Chk1 targets such as $\mathrm{Cdc} 25 \mathrm{C}$. Since Chk1 is an important cell cycle checkpoint protein, we also assessed the effects of either increasing or decreasing Wip1 expression on $\mathrm{G} 2 / \mathrm{M}$ and intra-S phase checkpoints. As expected, increased levels of Wip1 abrogated $\mathrm{G} 2 / \mathrm{M}$ and intra-S phase checkpoints, while decreased levels of Wip1 enhanced G2/M and intra-S phase checkpoints induced by both UV and IR treatment of cells [10]. Because Chk1 phosphorylates and activates p53, the inhibition of Chk1 by Wip1 also places Wip1 in a negative feedback regulatory loop for p53 (Fig. 2) [26].

Chk2 was also shown to directly interact with Wip1 in vitro and in vivo by Fujimoto et al. [9]. These investigators showed that Thr68, which is phosphorylated by ATM after IR treatment, is dephosphorylated efficiently by Wip1. Moreover, Wip1 also dephosphorylated several other S/TQ sites within Chk2. Overexpression of Wip1 was shown to suppress Chk2 kinase activity towards its substrate Cdc25C, while inhibition of Wip1 resulted in both increased and prolonged Chk2 kinase activity following IR. Interestingly, treatment of gamma-irradiated cells with Wip1 siRNA enhanced IR-induced apoptosis, suggesting that Wip 1 negatively regulates irradiation-induced apoptosis by dephosphorylating and inactivating Chk2. Several laboratories have corroborated the inhibition of Chk2 activity by Wip 1 and have shown that cancer cells with amplified Wip1 show reduced Chk2 activity [14, 49-51].

\subsubsection{S/TQ motif: $p 53$}

The tumor suppressor p53 is a central node in the DNA damage response and mediates an array of responses, including the activation of multiple cell cycle checkpoints, DNA repair and apoptosis [52]. The importance of p53 in cancer prevention is supported by the observation that about half of all human cancer patients harbor $p 53$ mutations [53]. Moreover, p53 deficient mice are highly susceptible to early onset spontaneous tumors [54]. In unstressed cells, p53 is maintained at low levels as a result of Mdm2-mediated ubiquitination and degradation [55]. When cells are confronted by genotoxic stress, ATM, ATR and Chk1/2 kinases phosphorylate p53. This phosphorylation, along with modifications of other residues, blocks the p53-Mdm2 interaction, leading to p53 stabilization and an increase in p53 activity [56].

We investigated whether Wip 1 dephosphorylated p53 at Ser15. In fact, both p53 phosphopeptides containing phosphoserine 15 and intact immunopurified p53 were efficiently dephosphorylated at Ser15 by purified Wip1 in vitro [10]. UV-irradiated cells exhibited reduced p53 Ser15 phosphorylation in the presence of overexpressed Wip1 and greatly augmented and sustained p53 Ser15 phosphorylation in the presence of Wip1 siRNA. As expected, increased Ser15 phosphorylation correlated with increased p53 protein levels in irradiated Wip1 siRNA treated cells.

\subsubsection{S/TQ motif: Mdm2}

The decreased stability of $\mathrm{p} 53$ in the presence of high Wip 1 levels led us to investigate whether or not the effects of Wip1 on p53 stability are mediated by $\mathrm{Mdm} 2 . \mathrm{Mdm} 2$ is an E3 ubiquitin ligase that specifically targets p53 for destruction [55]. Mdm2 binds to p53 and mediates its polyubiquitination as a prelude to its transport to the $26 \mathrm{~S}$ proteosome and proteolytic degradation. Importantly, DNA damage results in ATM phosphorylation of Mdm2 at Ser395 and this phosphorylation is associated with Mdm2 destabilization [31]. Phosphorylation at this site also inhibits Mdm2 interactions with $\mathrm{p} 53$. Thus, $\mathrm{p} 53$ is stabilized.

We had noted that reduction of Wip1 levels corresponded with increased sustained p53 protein levels and increased p53 transcriptional activity after IR-induced DNA damage $[8,49]$. One explanation for these observations was that Wip1 was affecting p53 stability through effects on Mdm2. To assess this possibility, we examined Wip1 interactions with Mdm2 and found that endogenous Wip1 and endogenous Mdm2 could form protein-protein interactions [8]. Moreover, Wip1 was shown to dephosphorylate Mdm2 at Ser395 both in vitro and in vivo. Dephosphorylation of Mdm2 by Wip1 was associated with decreased Mdm2 self-polyubiquitination and increased Mdm2 stability. Prevention of Mdm2 Ser395 dephosphorylation by Wip1 siRNA treatment destabilized Mdm2 following irradiation [8]. As expected, Wip1 overexpression increased Mdm2 interaction with $\mathrm{p} 53$ and increased $\mathrm{p} 53$ polyubiquitination, facilitating p53 proteolytic degradation. Thus, a primary role of Wip1 is to inhibit p53 stability in part through augmenting Mdm2 stability as a consequence of Mdm2 Ser395 dephosphorylation (Fig. 2).

\subsubsection{S/TQ motif: ATM}

ATM is a sensor kinase that is rapidly activated by DNA double strand breaks in part through autophosphorylation at Ser1981 (or Ser1987 in the mouse). Activated ATM then phosphorylates a diverse array of effector molecules that induce cell cycle arrest, DNA repair, DNA replication, and apoptosis. Activated ATM phosphorylates its targets at S/ TQ sites and it has recently been shown by Elledge and colleagues in a global proteomic screen that ATM/ATR phosphorylates over 700 protein targets with widely different functions [4].

Bulavin and colleagues have demonstrated that Wipl null mouse embryo fibroblasts (MEFs) treated with IR 
exhibit higher levels of Ser1987 phosphorylation, indicating higher levels of ATM activity [7]. Wip1 was shown to directly interact with ATM and its overexpression resulted in decreased levels of Ser1981 phosphorylation following IR treatment. Conversely, downregulation of Wip1 using siRNA resulted in increased Ser1981 phosphorylation. Moreover, immunopurified ATM was efficiently dephosphorylated at Ser1987 by purified Wip1, as was a phosphopeptide derived from this part of ATM. More recently, Shreeram et al. [57] have also shown that Wip1 dephosphorylates human ATM at Ser367 as well as Ser1981. The authors concluded that Wip1 was important in resetting ATM phosphorylation after repair of DNA damage.

\section{Wip1 is an oncogene}

While a significant number of tyrosine phosphatases are associated with cancer initiation or development [58], few serine/threonine phosphatases have been directly associated with oncogenesis. The only well characterized serine/ threonine phosphatase involved in oncogenic signaling is the phosphatase PP2A. PP2A has tumor suppressor activity and its inactivation has been associated with transformation of human primary cells [59]. It has also been shown to be either mutated or downregulated in some human cancers. Among the type $2 \mathrm{C}$ phosphatases, Wip1 appears to be the only one described so far with bona fide oncogenic function. The regulatory functions of Wip1 in the ATMCHK1/2-p53 and p38 MAPK-ARF/p16 ${ }^{\text {INK4A }}$ signaling pathways would argue that this protein may possess major oncogenic potential.

The first evidence of an oncogenic role for Wip1 was published in a pair of papers by Bulavin et al. [17] and Li et al. [60]. Bulavin et al. used tissue microarray profiling to show that 37 of 326 primary breast tumors $(11.3 \%)$ had Wipl gene amplification. Similarly, Li et al., using DNA microarray analysis, showed that Wipl was amplified at least 2.5 fold in 27 of $164(16 \%)$ primary breast cancers. Both laboratories demonstrated that overexpression of Wip 1 mRNA correlated well with Wipl gene amplification. Interestingly, only one of eight tumors with Wipl amplification examined by Bulavin et al. had a $p 53$ mutation. The infrequent nature of $\mathrm{p} 53$ mutations in tumors with Wip 1 amplification suggests that Wip1 may promote human tumors through its ability to inhibit p53, circumventing selective pressure to mutate $p 53$ during tumor progression. Wip1 amplification in this context is reminiscent of tumors with $M d m 2$ amplification, where Mdm2 promotes degradation of $\mathrm{p} 53$ and few of these tumors exhibit $p 53$ mutations [61]. Since these initial reports, other groups have confirmed amplification and overexpression of the Wipl gene in breast cancers [62, 63]. Rauta et al. [62] showed Wipl gene was amplified in $11 \%$ of breast cancers and this amplification was highly associated with ErbB2 amplification. Moreover, these investigators observed that breast cancers with Wipl amplification had a significantly poorer prognosis than those without Wipl amplification, though a breast cancer study by $\mathrm{Yu}$ et al. [63] failed to detect an effect of Wip1 overexpression on prognosis. In addition to breast cancers, Wip1 amplification and overexpression have been observed in ovarian clear cell adenocarcinomas [64], neuroblastomas [65], pancreatic adenocarcinomas [66], gastric carcinomas [51], and medulloblastomas [67-69] (Table 2). As shown in Table 2, where it was examined, tumors with Wipl amplification rarely contained $p 53$ mutations and often exhibited poorer prognosis than their counterparts with normal Wip1. Since only a handful of tumor types have been reported, it remains to be seen whether Wipl amplification and overexpression occurs in most tumor types

Table 2 Human tumors with Wip1 gene amplification and/or overexpression

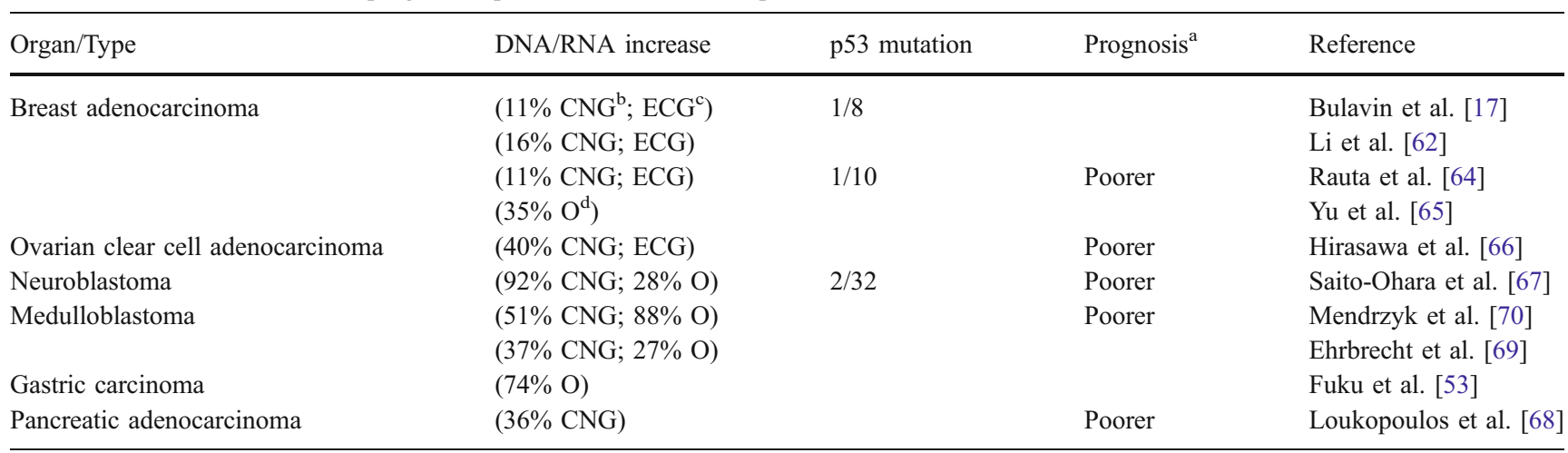

a Prognosis: "Poorer" indicates individuals with tumors with increased Wip1 copy number and/or expression have significantly poorer prognosis than all individuals with that type of tumor

${ }^{\mathrm{b}} \mathrm{CNG}$ : Wip1 DNA copy number gain (compared to DNA in normal tissues)

${ }^{c}$ ECG: increased Wip1 RNA expression significantly correlates with copy number gain

${ }^{\mathrm{d}} \mathrm{O}$ : percentage of tumors with Wip1 RNA overexpression 
or only in a subset. Certainly, tumors with a low frequency of p53 mutations might circumvent $p 53$ mutation or loss by Wip1 functional inactivation of $\mathrm{p} 53$ and these tumors would be good candidates for further investigation.

In their papers describing the initial discovery of Wipl amplification and overexpression in breast cancers, Bulavin et al. [17] and $\mathrm{Li}$ et al. [60] were also able to show that Wip1 can collaborate with known oncogenes such as Ras, Myc and Neu to transform rodent wild type primary fibroblasts and induce anchorage-independent growth in soft agar. It was also shown by both groups that overexpression of Wip 1 could abrogate Ras-induced senescence of primary cells and could prevent apoptosis induced by serum starvation. Interestingly, transformation assays on p53 null MEFs showed that while Ras, Neu and Myc oncogenes could individually transform these cells, Wip1 could not [17]. These results argued that Wip1 is primarily oncogenic as a result of its ability to inhibit p53 signaling. In later studies, our laboratory was able to show that Wip1 transformation of primary rat embryo fibroblasts, in conjunction with the adenoviral E1A oncogene, was dependent on the phosphatase activity of Wip1 [49]. In contrast to wild-type Wip1, the phosphatase-dead mutant Wip1 (D307A) failed to transform primary fibroblasts.

To further demonstrate that Wip1 is oncogenic in an in vivo context, Demidov et al. [70] overexpressed Wipl as a transgene in the mouse mammary gland. While the Wip 1 transgenic mice did not develop spontaneous mammary tumors, the appearance of mammary tumors was accelerated when these animals were crossed with mammary tumor susceptible ErbB2 transgenic mice. Interestingly, the tumor promoting effects of the Wip1 transgene in the ErbB2 transgenics could be lost by further crossing in a constitutively activated MKK6 transgene [70]. MKK6 activates p38 MAP kinase and thus nullifies the effects of Wip1 dephosphorylation of $\mathrm{p} 38$, demonstrating the importance of Wip1 in regulating p38 signaling as well as p53 signaling in this particular model.

\section{Mechanisms of Wip1 oncogenicity}

Wip1 overexpression in MEFs and in transgenic mice promotes cell transformation and accelerated cancer progression [17, 49, 60, 70]. Moreover, a number of human cancers contain amplified and overexpressed Wip1 (Table 2). Generally, these tumors do not contain p53 mutations, suggesting that overexpressed Wip1 inhibits p53 during tumor progression, consistent with the fact that Wip1 suppresses p53 activity in the normal cellular context (Fig. 2). As an alternative approach to assess Wip1 function in promoting tumorigenesis, Wipl-deficient mice were generated in our laboratory. Wip1 null mice are viable but show some postnatal abnormalities, including variable male runting, male reproductive organ atrophy, reduced male fertility, and reduced male longevity [71]. The Wipl null mice also showed increased susceptibility to pathogens and diminished T- and B-cell function.

Fibroblasts derived from Wipl null embryos showed reduced growth rates, reduced colony forming ability, and premature senescence compared to their wild-type counterparts [12, 71]. In addition, Wip1 null MEFs exhibited an enhanced G1 checkpoint response to ionizing radiation. Bulavin et al. [12] showed that Wip1 null fibroblasts were significantly more resistant to transformation by various combinations of oncogenes compared to wild-type MEFs. Hras1 plus the adenoviral E1A oncogene transformed Wip1-/- MEFs displayed increased expression of $\mathrm{p} 53$ and cyclin dependent kinase inhibitors $\mathrm{p} 21, \mathrm{p} 16^{\mathrm{INK} 4 \mathrm{~A}}$, and p19 ${ }^{\text {ARF }}$ compared to Wip1+/+ MEFs. In addition, the p38 MAP kinase showed increased phosphorylation in Wip1-/MEFs [12]. Increases in p53, p21, and phosphorylated p38 MAP kinase in Wip1 null MEFs are supported by the fact that Wip1 directly dephosphorylates p38 and p53 and regulators of p53 (ATM, Chk1, Chk2). Since p21 is transcriptionally upregulated by $\mathrm{p} 53$, the increase in its levels is attributable to p53 activation.

One interesting result in these transformed Wip1 null MEF studies was the increase in $\mathrm{p} 19^{\mathrm{ARF}}$ and $\mathrm{p} 16^{\mathrm{INK} 4 \mathrm{a}}$ levels. Wip1 regulation of these cyclin dependent kinase inhibitors appears to be at the transcriptional level, as transformed Wip1 null MEFs showed a three- to fourfold enhancement of transfected p16 promoter driven luciferase expression and $\mathrm{p} 19$ promoter driven CAT expression when compared to wild-type MEFs. Bulavin et al. [12] further showed that oncogene transformed $p 53$ null MEFs produce tumors when transplanted into nude mice, while transformed doubly null p53 and Wip1 MEFs were resistant to tumors. Thus, Wip1 must regulate other pathways in addition to $\mathrm{p} 53$ to promote tumorigenesis, at least in this MEF model system. In contrast to p53-/- Wip1-/- MEFs, MEFs from Cdkn2a-l- (null for both p16 and p19, encoded from the same locus) Wip1-/- mice readily formed nude mouse tumors after oncogene transformation. This indicated that $\mathrm{p} 16$ or $\mathrm{p} 19$ or both genes were responsible for the Wip1 null MEF resistance to tumors. Subsequent experiments showed that much (though not all) of the transformation resistance was provided by $\mathrm{p} 19^{\mathrm{ARF}}$ [12].

Bulavin et al. [12] also tested the effects of Wipl deficiency on tumorigenesis in an in vivo context. Three mammary tumor susceptible models, MMTV promoter driven ErbB2, Hras1, and Wnt1 transgenic mice were crossed to Wipl deficient mice and oncogene driven mammary tumorigenesis was examined in the presence and absence of Wip1. Wipl female null mice were 
considerably more resistant to mammary tumors in the presence of the MMTV-HRas1 and MMTV-ErbB2 transgenes than were their Wipl wild-type counterparts. However, Wip1 female null mice with the MMTV-Wnt1 transgene developed mammary cancers at the same rate as transgenic Wip1 wild-type females. Interestingly, the Wip1 null MMTV-ErbB2 tumors displayed a reduced mitotic index and an increased apoptotic cell index compared to the Wip1 wild-type MMTV-ErbB2 tumors. Moreover, p16 ${ }^{\text {INK4a }}$ protein levels in the Wip1 null tumors were low or absent, suggesting that loss or inactivation of high p16 expression (probably by p16 promoter methylation) is a likely prerequisite for tumor progression in this model. It was also observed that these Wip1 null mammary tumors also contained high levels of activated p38 MAP kinase (as indicated by increased levels of phosphorylated p38). Inhibition of $\mathrm{p} 38$ in the MMTV-ErbB2 Wip1 null mice by repeated injection of the inhibitor SB203580 resulted in the accelerated development of mammary tumors compared to water injected mice of the same genotype. Thus, constitutive activation of p38 MAP kinase in the absence of Wip1 may contribute to tumor resistance in the Wip1-/- MMTVErbB2 mice.

In another transgenic mouse model Shreeram et al. [57] examined lymphoma incidence in Wipl+/+, Wipl+/- and Wip1-/- mice bearing the E $\mu$-myc transgene in which Myc overexpression is restricted to B lymphocytes. Wip 1+/- and Wip1-/- mice exhibited a significant delay in E $\mu-M y c-$ induced B cell lymphoma incidence. The median lifespan

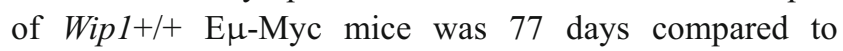
107 days for Wip 1+/- E $\mu-M y c$ mice and 138 days for Wip1-/- E $\mu-M y c$ mice [14]. Subsequent crosses of the Wip1-deficient E $\mu$-Myc transgenic mice to p53, p19 ${ }^{\mathrm{ARF}}$, and ATM-deficient mice showed that Wipl deficiency suppressed E $\mu$-Myc-induced lymphomagenesis in an ATM and p53-dependent, but ARF-independent manner [57]. Thus, overexpression of Wip1 in an oncogenic context could contribute to tumor promotion by inhibiting both $\mathrm{p} 53$ and ATM functions.
In addition to delaying oncogene-induced tumors, we found that Wipl absence also resulted in far fewer spontaneous cancers than in mice with normal levels of Wip1 [49]. Lifelong monitoring of Wip $1+/+$ mice recorded a $45 \%$ incidence of spontaneous cancers, while Wip $1+/-$ and Wip1-/- mice had a cancer incidence of $25 \%$ and $10 \%$, respectively. These differences in tumor incidence between the Wip1+/+ and Wip1-/- mice were significant $(P=0.016)$. These results suggest that the absence of Wip1 confers a significant degree of resistance to cancer development over the lifespan of the mouse.

Part of the cancer resistance phenotypes of the Wip1 null mice may have been due to an enhanced DNA damage response in Wip1-/- tissues. Following whole body irradiation with $5 \mathrm{~Gy}$, Wip1-/- tissues often exhibited increased phosphorylation of the DNA damage response proteins p53 (Ser15), Chk1 (Ser345), Chk2 (Thr68), and p38 (Thr180) compared to similar Wip1+/+ tissues [49]. These results suggested that an enhanced DNA damage response might be one mechanism for the cancer resistance of Wip1 null mice, consistent with recent findings that the DNA damage response may be an important early failsafe system in preventing cancer progression $[5,6]$.

In summary, the studies described in this section and the previous section provide compelling evidence that Wip1 is a human oncogene. Table 3 recapitulates some of the evidence provided above in support of Wip1 oncogenic function. Its amplification and overexpression in human tumors, its clear effects on transformation of cells in culture and effects on tumorigenesis in animal models, and its ability to inhibit the activity of multiple tumor suppressors clearly define it as an oncogene. Perhaps the most important tumor suppressor modulated by Wip1 is the p53 protein. As shown in Fig. 2, Wip1 inhibits upstream kinase activators of p53 (ATM, p38, Chk1, Chk2), dephosphorylates p53 itself at Ser15, stabilizes a key mediator of p53 degradation, Mdm2, and inhibits the ARF upstream activator of $\mathrm{p} 53$. Its inhibition of $\mathrm{p} 16^{\mathrm{INK} 4 \mathrm{a}}$ levels also suggests Wip1 activity in suppressing retinoblastoma $(\mathrm{Rb})$ tumor suppressor regulated pathways.

Table 3 Evidence that the Wip1 gene is an oncogene

\begin{tabular}{ll}
\hline Evidence & References \\
\hline 1. Wip1 specifically inhibits p53 signaling by multiple mechanisms & {$[8-12,17]$} \\
2. Wip1 inhibits the activity of other tumor suppressors (ARF, p16 ${ }^{\mathrm{INK} 4 \mathrm{~A}}$ ) & {$[12]$} \\
3. Wip1 abrogates DNA damage response pathways and cell cycle checkpoints & {$[10,25,51]$} \\
4. Wip1 can transform primary rodent fibroblasts in conjunction with other oncogenes & {$[17,51,62]$} \\
5. Wip1 accelerates tumorigenesis in a mammary tumor susceptible model & {$[72]$} \\
6. Wip1 is amplified and overexpressed in multiple types of human tumors & {$[17,62,64-71]$} \\
7. Wip1 amplification and overexpression is often associated with poorer prognosis & {$[64,66,67,68,70]$} \\
8. Wip1 null primary embryo fibroblasts are resistant to transformation by oncogenes & {$[12]$} \\
9. Wip1 null mice are resistant to spontaneous and oncogene-induced tumors & {$[12,51,59]$} \\
\hline
\end{tabular}




\section{Wip1 as a target for cancer chemotherapeutic approaches}

Because Wip1 inhibits so many tumor suppressor molecules (p53, ATM, p16 ${ }^{\mathrm{INK} 4 \mathrm{~A}}, \mathrm{p} 14 / \mathrm{p} 19^{\mathrm{ARF}}$ ), targeting Wip1 function in cancer cells may be an effective way to enhance tumor suppressor function, resulting in enhanced cancer cell arrest and/or apoptosis. A number of laboratories have begun to experiment with this approach by developing and characterizing inhibitors of Wip1 phosphatase activity. Yamaguchi et al. [24] have developed a series of substituted linear and circular phosphopeptides that variably inhibited Wip1 activity. Optimization experiments resulted in two thioether cyclic phosphopeptides with a pSIpY core motif with essentially $100 \%$ inhibition of recombinant Wip1 phosphatase activity. Molecular modeling experiments indicated close interaction of the cyclic inhibitor with the key postulated catalytic residues (R76 and K238) in Wip1. Moreover, the inhibitor was specific for Wip1 and did not inhibit PP2A or PP2C $\alpha$ [24].

Another approach was taken by Bulavin and colleagues who screened a diversity set library of 1990 compounds and identified 14 that could completely inhibit Wip 1 phosphatase activity [72]. Two of these compounds were highly effective at concentrations as low as $0.5 \mu \mathrm{M}$ and most of these hits did not inhibit PP2C $\alpha$ and PP2A. When transformed MEFs were incubated with each of the 14 Wip1 inhibitors and tested for p38 MAPK phosphorylation (the prototype Wip1 target), only 5 of the compounds increased phosphorylation of $\mathrm{p} 38$. The most effective of these (compound $\mathrm{M}$ ) was tested on various breast cancer cell lines and found to reduce cell viability by $30-50 \%$ in some lines and could also potentiate the anti-proliferative effects of the anti-cancer drug doxorubicin. Finally, compound $\mathrm{M}$ was injected into both mammary tumor susceptible MMTV-Neu mice and mouse xenograft models and was effective in reducing both tumor cell proliferation and tumor volume [72].

Another large high throughput screen of 65,500 compounds by Rayter et al. [73] identified six compounds that demonstrated strong inhibition of Wip1 phosphatase activity. However, only two of these compounds showed growth inhibitory activity on cancer cell lines. Of these, one specifically inhibited the growth of cells overexpressing Wip1, an effect that was lost in the presence of the p38 MAP kinase inhibitor SB203580. This indicated that suppression of p38 signaling by Wip1 is likely to be an important component of tumor promotion in some Wip1 overexpressing human cancer cells. The identification of novel Wip1 small molecule inhibitors is an encouraging advance and suggests that this approach merits further consideration for testing in human cancer patients.

\section{Other Wip1 biological functions}

Aside from its clear importance in DNA damage response signaling and oncogenesis, the phenotypes observed in Wip1 knockout mice revealed other key physiological roles for Wip1. The Wipl knockout mice display a range of abnormalities, including variable male runting, male reproductive organ atrophy with reduced male fertility as well as modestly diminished male longevity [71]. The reproductive defects of the Wip1-/- mice are only seen in older males and are presumably related to the abnormal seminiferous tubules and epididymi with a small number of mature spermatozoa that arise in these animals. The mechanisms of runting and reduced longevity seen in the null males may be a result of hormone level imbalance or deficient steroid receptor activation. Proia et al. [74] did demonstrate a rather unexpected regulatory effect of Wip1 on the progesterone receptor. This study showed that overexpression of Wip1 stimulates steroid receptor activity, by enhancing the intrinsic activity of p160 coactivators such as steroid receptor coactivator- 1 . One result of this activation is that Wip1 positively regulates the activity of estrogen, progesterone, and androgen receptors. This function appears to be independent of p38 MAPK because SB202190 (a potent p38MAPK inhibitor) is unable to reverse the inhibition of the progesterone receptor activity elicited by reducing Wip 1 expression in MCF-7 cells.

Mice lacking Wipl also showed immunological defects. The Wip1 null mice occasionally exhibited ulcerated skin lesions, disorganized and hyperplastic lymphoid organs, and increased inflammation in normal organs. $\mathrm{B}$ and $\mathrm{T}$ lymphocytes from Wip1-/- mice displayed a variety of unbalanced and ineffective responses to antigenic and mitogenic stimulation [71]. Moreover, Wip1 null mice were more likely to die from influenza virus infection than their normal counterparts.

Schito et al. [75] in a more extended analysis of immune defects in the Wip1 null mice, showed that Wip1 is vital during the double negative to double positive $\mathrm{T}$ cell transition. Young Wip1 null mice had fewer splenic T cells and their thymi were smaller with fewer double positive (DP) and single positive (SP) CD4+ and CD8+ T cells. A partial block in transition from double negative (DN) to double positive $\mathrm{T}$ cells was noted and this correlates with a peak in Wip1 mRNA expression in the late DN stages of T cell maturation. DP T cells that did mature were found to have cell cycle abnormalities and increased apoptotic rates. Importantly, when the Wip1 null mice were crossed into a p53 null strain, many of the thymic and T cell deficiencies were rescued, indicating that a major component of the Wip1-/- T cell phenotypes were likely to be due to increased p53 activity. 


\section{Conclusions, future prospects}

Since the discovery of Wip 1 by the Appella laboratory in 1997 there have been many advances in our understanding of how this p53-induced phosphatase functions. Yet in the decade or so since its discovery, there have been fewer than 50 papers associated with the study of Wip1, indicating that we have only scratched the surface in terms of gaining a complete understanding of the biological role of this protein. We have learned that Wip1/PPM1D is an oncogene that functions in part by suppressing major tumor suppressors that include p53. It also plays a homeostatic role in reversing the effects of the ATM/ATR-initiated DNA damage response pathway. This homeostatic role is generally benign until somehow the Wipl gene becomes amplified and upregulated. Why and how this abnormal Wip1 alteration occurs in tumors is unclear, but should be of much interest in future studies.

Many important questions remain to be answered. The structure, catalytic activities and functional domains of Wip1 are still poorly understood. What does the C-terminal non-catalytic domain do? Are pTXpY and pS/pTQ the only target motifs recognized by Wip1 or are there others? And what are the other target proteins? The best guess is that there are likely to be hundreds of targets, if not more. Does Wip1 have other undiscovered functions? And perhaps most importantly, from a disease perspective, how many human cancers exhibit Wip1 overexpression, what are the mechanisms for Wip1-mediated oncogenesis, and how can our knowledge of these mechanisms assist us in designing novel therapies to fight cancer? The answers to these questions in the coming years should result in increased interest in this heretofore little studied protein.

Acknowledgements This work was supported by an NIH R01 grant (CA100420), a James S. McDonnell Foundation grant to L.A.D. and a D.O.D. Breast Cancer Research Program pre-doctoral fellowship to T.A.N.

Open Access This article is distributed under the terms of the Creative Commons Attribution Noncommercial License which permits any noncommercial use, distribution, and reproduction in any medium, provided the original author(s) and source are credited.

\section{References}

1. Abraham, R. T. (2001). Cell cycle checkpoint signaling through the ATM and ATR kinases. Genes \& Development, 15, 2177-2196.

2. Shiloh, Y. (2003). ATM and related protein kinases: safeguarding genome integrity. Nature Reviews Cancer, 3, 155-168.
3. Kim, S. T., Lim, D. S., Canman, C. E., \& Kastan, M. B. (1999). Substrate specificities and identification of putative substrates of ATM kinase family members. Journal of Biological Chemistry, 274, 37538-37543.

4. Matsuoka, S., Ballif, B. A., Smogorzewska, A., McDonald 3rd, E. R., Hurov, K. E., Luo, J., et al. (2007). ATM and ATR substrate analysis reveals extensive protein networks responsive to DNA damage. Science, 316, 1160-1166.

5. Gorgoulis, V. G., Vassiliou, L. V., Karakaidos, P., Zacharatos, P., Kotsinas, A., Liloglou, T., et al. (2005). Activation of the DNA damage checkpoint and genomic instability in human precancerous lesions. Nature, 434, 907-913.

6. Bartkova, J., Horejsi, Z., Koed, K., Kramer, A., Tort, F., Zieger, $\mathrm{K}$., et al. (2005). DNA damage response as a candidate anti-cancer barrier in early human tumorigenesis. Nature, 434, 864-870.

7. Shreeram, S., Demidov, O. N., Hee, W. K., Yamaguchi, H., Onishi, N., Kek, C., et al. (2006). Wip1 phosphatase modulates ATM-dependent signaling pathways. Molecular Cell, 23, 757-764.

8. Lu, X., Ma, O., Nguyen, T. A., Jones, S. N., Oren, M., \& Donehower, L. A. (2007). The Wip1 phosphatase acts as a gatekeeper in the p53-Mdm2 autoregulatory loop. Cancer Cell, 12, 342-354.

9. Fujimoto, H., Onishi, N., Kato, N., Takekawa, M., Xu, X. Z., Kosugi, A., et al. (2006). Regulation of the antioncogenic Chk2 kinase by the oncogenic Wip1 phosphatase. Cell Death and Differentiation, 13, 1170-1180.

10. Lu, X., Nannenga, B., \& Donehower, L. A. (2005). PPM1D dephosphorylates Chk1 and p53 and abrogates cell cycle checkpoints. Genes \& Development, 19, 1162-1174.

11. Takekawa, M., Adachi, M., Nakahata, A., Nakayama, I., Itoh, F., Tsukuda, H., et al. (2000). p53-inducible wip1 phosphatase mediates a negative feedback regulation of p38 MAPK-p53 signaling in response to UV radiation. EMBO Journal, 19, 6517-6526.

12. Bulavin, D. V., Phillips, C., Nannenga, B., Timofeev, O., Donehower, L. A., Anderson, C. W., et al. (2004). Inactivation of the Wip1 phosphatase inhibits mammary tumorigenesis through p38 MAPK-mediated activation of the p16(Ink4a)-p19 (Arf) pathway. Nature Genetics, 36, 343-350.

13. Fiscella, M., Zhang, H., Fan, S., Sakaguchi, K., Shen, S., Mercer, W. E., et al. (1997). Wip1, a novel human protein phosphatase that is induced in response to ionizing radiation in a p53-dependent manner. Proceedings of the National Academy of Sciences of the United States of America, 94, 6048-6053.

14. Yoda, A., Xu, X. Z., Onishi, N., Toyoshima, K., Fujimoto, H., Kato, N., et al. (2006). Intrinsic kinase activity and SQ/TQ domain of Chk2 kinase as well as N-terminal domain of Wip1 phosphatase are required for regulation of Chk2 by Wip1. Journal of Biological Chemistry, 281, 24847-24862.

15. Yamaguchi, H., Minopoli, G., Demidov, O. N., Chatterjee, D. K., Anderson, C. W., Durell, S. R., et al. (2005). Substrate specificity of the human protein phosphatase 2Cdelta, Wip1. Biochemistry, 44, 5285-5294.

16. Choi, J., Appella, E., \& Donehower, L. A. (2000). The structure and expression of the murine wildtype p53-induced phosphatase 1 (Wip1) gene. Genomics, 64, 298-306.

17. Bulavin, D. V., Demidov, O. N., Saito, S., Kauraniemi, P., Phillips, C., Amundson, S. A., et al. (2002). Amplification of PPM1D in human tumors abrogates p53 tumor-suppressor activity. Nature Genetics, 31, 210-215.

18. Barford, D., Das, A. K., \& Egloff, M. P. (1998). The structure and mechanism of protein phosphatases: insights into catalysis and regulation. Annual Review of Biophysics and Biomolecular Structure, 27, 133-164.

19. Moorhead, G. B., Trinkle-Mulcahy, L., \& Ulke-Lemee, A. (2007). Emerging roles of nuclear protein phosphatases. Nature Reviews Molecular Cell Biology, 8, 234-244. 
20. Barford, D. (1996). Molecular mechanisms of the protein serine/ threonine phosphatases. Trends in Biochemical Sciences, 21, 407-412.

21. Jackson, M. D., \& Denu, J. M. (2001). Molecular reactions of protein phosphatases - insights from structure and chemistry. Chemical Reviews, 101, 2313-2340.

22. Takekawa, M., Maeda, T., \& Saito, H. (1998). Protein phosphatase 2Calpha inhibits the human stress-responsive p38 and JNK MAPK pathways. EMBO Journal, 17, 4744-4752.

23. Hanada, M., Kobayashi, T., Ohnishi, M., Ikeda, S., Wang, H., Katsura, K., et al. (1998). Selective suppression of stress-activated protein kinase pathway by protein phosphatase $2 \mathrm{C}$ in mammalian cells. FEBS Letters, 437, 172-176.

24. Yamaguchi, H., Durell, S. R., Feng, H., Bai, Y., Anderson, C. W., \& Appella, E. (2006). Development of a substrate-based cyclic phosphopeptide inhibitor of protein phosphatase 2Cdelta, Wip1. Biochemistry, 45, 13193-13202.

25. Lu, X., Bocangel, D., Nannenga, B., Yamaguchi, H., Appella, E., \& Donehower, L. A. (2004). The p53-induced oncogenic phosphatase PPM1D interacts with uracil DNA glycosylase and suppresses base excision repair. Molecular Cell, 15, 621-634.

26. Lu, X., Nguyen, T. A., \& Donehower, L. A. (2005). Reversal of the ATM/ATR-mediated DNA damage response by the oncogenic phosphatase PPM1D. Cell Cycle, 4, 1060-1064.

27. Siliciano, J. D., Canman, C. E., Taya, Y., Sakaguchi, K., Appella, E., \& Kastan, M. B. (1997). DNA damage induces phosphorylation of the amino terminus of p53. Genes \& Development, 11, 3471-3481.

28. Bulavin, D. V., Saito, S., Hollander, M. C., Sakaguchi, K., Anderson, C. W., Appella, E., et al. (1999). Phosphorylation of human $\mathrm{p} 53$ by $\mathrm{p} 38$ kinase coordinates N-terminal phosphorylation and apoptosis in response to UV radiation. EMBO Journal, 18, 6845-6854.

29. Liu, Q., Guntuku, S., Cui, X. S., Matsuoka, S., Cortez, D., Tamai, $\mathrm{K}$., et al. (2000). Chk1 is an essential kinase that is regulated by Atr and required for the G(2)/M DNA damage checkpoint. Genes \& Development, 14, 1448-1459.

30. Shieh, S. Y., Ahn, J., Tamai, K., Taya, Y., \& Prives, C. (2000). The human homologs of checkpoint kinases Chk1 and Cds1 (Chk2) phosphorylate p53 at multiple DNA damage-inducible sites. Genes \& Development, 14, 289-300.

31. Maya, R., Balass, M., Kim, S. T., Shkedy, D., Leal, J. F., Shifman, O., et al. (2001). ATM-dependent phosphorylation of Mdm2 on serine 395: Role in p53 activation by DNA damage. Genes \& Development, 15, 1067-1077.

32. Derijard, B., Raingeaud, J., Barrett, T., Wu, I. H., Han, J., Ulevitch, R. J., et al. (1995). Independent human MAP-kinase signal transduction pathways defined by MEK and MKK isoforms. Science, 267, 682-685.

33. Raingeaud, J., Gupta, S., Rogers, J. S., Dickens, M., Han, J., Ulevitch, R. J., et al. (1995). Pro-inflammatory cytokines and environmental stress cause p38 mitogen-activated protein kinase activation by dual phosphorylation on tyrosine and threonine. Journal of Biological Chemistry, 270, 7420-7426.

34. She, Q. B., Chen, N., \& Dong, Z. (2000). ERKs and p38 kinase phosphorylate $\mathrm{p} 53$ protein at serine 15 in response to UV radiation. Journal of Biological Chemistry, 275, 20444-20449.

35. Huang, C., Ma, W. Y., Maxiner, A., Sun, Y., \& Dong, Z. (1999). p38 kinase mediates UV-induced phosphorylation of $\mathrm{p} 53$ protein at serine 389. Journal of Biological Chemistry, 274, 12229-12235.

36. Krokan, H. E., Drablos, F., \& Slupphaug, G. (2002). Uracil in DNA-occurrence, consequences and repair. Oncogene, 21, 8935-8948.

37. Rual, J. F., Venkatesan, K., Hao, T., Hirozane-Kishikawa, T., Dricot, A., Li, N., et al. (2005). Towards a proteome-scale map of the human protein-protein interaction network. Nature, 437, 11731178 .
38. Lu, X., Nguyen, T. A., Appella, E., \& Donehower, L. A. (2004). Homeostatic regulation of base excision repair by a p53-induced phosphatase: Linking stress response pathways with DNA repair proteins. Cell Cycle, 3, 1363-1366.

39. Bartek, J., \& Lukas, J. (2003). Chk1 and Chk2 kinases in checkpoint control and cancer. Cancer Cell, 3, 421-429.

40. Zhao, H., \& Piwnica-Worms, H. (2001). ATR-mediated checkpoint pathways regulate phosphorylation and activation of human Chk1. Molecular Cell Biology, 21, 4129-4139.

41. Karlsson-Rosenthal, C., \& Millar, J. B. (2006). Cdc25: mechanisms of checkpoint inhibition and recovery. Trends in Cell Biology, 16, 285-292.

42. Melchionna, R., Chen, X. B., Blasina, A., \& McGowan, C. H. (2000). Threonine 68 is required for radiation-induced phosphorylation and activation of Cds1. Nature Cell Biology, 2, 762765.

43. Matsuoka, S., Rotman, G., Ogawa, A., Shiloh, Y., Tamai, K., \& Elledge, S. J. (2000). Ataxia telangiectasia-mutated phosphorylates Chk2 in vivo and in vitro. Proceedings of the National Academy of Sciences of the United States of America, 97, 1038910394.

44. Ahn, J. Y., Schwarz, J. K., Piwnica-Worms, H., \& Canman, C. E. (2000). Threonine 68 phosphorylation by ataxia telangiectasia mutated is required for efficient activation of Chk2 in response to ionizing radiation. Cancer Research, 60, 5934-5936.

45. Gatei, M., Sloper, K., Sorensen, C., Syljuasen, R., Falck, J., Hobson, K., et al. (2003). Ataxia-telangiectasia-mutated (ATM) and NBS1-dependent phosphorylation of Chk1 on Ser-317 in response to ionizing radiation. Journal of Biological Chemistry, 278, 14806-14811.

46. Hirao, A., Cheung, A., Duncan, G., Girard, P. M., Elia, A. J., Wakeham, A., et al. (2002). Chk2 is a tumor suppressor that regulates apoptosis in both an ataxia telangiectasia mutated (ATM)-dependent and an ATM-independent manner. Molecular Cell Biology, 22, 6521-6532.

47. Cuadrado, M., Martinez-Pastor, B., \& Fernandez-Capetillo, O. (2006). "ATR activation in response to ionizing radiation: still ATM territory". Cell Division, 1, 7.

48. Jazayeri, A., Falck, J., Lukas, C., Bartek, J., Smith, G. C., Lukas, J., et al. (2006). ATM- and cell cycle-dependent regulation of ATR in response to DNA double-strand breaks. Nature Cell Biology, 8, 37-45.

49. Nannenga, B., Lu, X., Dumble, M., Van Maanen, M., Nguyen, T. A., Sutton, R., et al. (2006). Augmented cancer resistance and DNA damage response phenotypes in PPM1D null mice. Molecular Carcinogenesis, 45, 594-604.

50. Oliva-Trastoy, M., Berthonaud, V., Chevalier, A., Ducrot, C., Marsolier-Kergoat, M. C., Mann, C., et al. (2007). The Wip1 phosphatase (PPM1D) antagonizes activation of the Chk2 tumour suppressor kinase. Oncogene, 26, 1449-1458.

51. Fuku, T., Semba, S., Yutori, H., \& Yokozaki, H. (2007). Increased wild-type p53-induced phosphatase 1 (Wip1 or PPM1D) expression correlated with downregulation of checkpoint kinase 2 in human gastric carcinoma. Pathology International, 57, 566-571.

52. Horn, H. F., \& Vousden, K. H. (2007). Coping with stress: Multiple ways to activate p53. Oncogene, 26, 1306-1316.

53. Olivier, M., Hussain, S. P., Caron de Fromentel, C., Hainaut, P., \& Harris, C. C. (2004). TP53 mutation spectra and load: A tool for generating hypotheses on the etiology of cancer. IARC Scientific Publications, 157, 247-270.

54. Donehower, L. A., Harvey, M., Slagle, B. L., McArthur, M. J., Montgomery Jr., C. A., Butel, J. S., et al. (1992). Mice deficient for p53 are developmentally normal but susceptible to spontaneous tumours. Nature, 356, 215-221.

55. Bond, G. L., Hu, W., \& Levine, A. J. (2005). MDM2 is a central node in the p53 pathway: 12 years and counting. Current Cancer Drug Targets, 5, 3-8. 
56. Shieh, S. Y., Ikeda, M., Taya, Y., \& Prives, C. (1997). DNA damage-induced phosphorylation of p53 alleviates inhibition by MDM2. Cell, 91, 325-334.

57. Shreeram, S., Hee, W. K., Demidov, O. N., Kek, C., Yamaguchi, H., Fornace Jr., A. J., et al. (2006). Regulation of ATM/p53dependent suppression of myc-induced lymphomas by Wip1 phosphatase. Journal of Experimental Medicine, 203, 2793-2799.

58. Ostman, A., Hellberg, C., \& Bohmer, F. D. (2006). Protein-tyrosine phosphatases and cancer. Nature Reviews Cancer, 6, 307-320.

59. Arroyo, J. D., \& Hahn, W. C. (2005). Involvement of PP2A in viral and cellular transformation. Oncogene, 24, 7746-7755.

60. Li, J., Yang, Y., Peng, Y., Austin, R. J., van Eyndhoven, W. G., Nguyen, K. C., et al. (2002). Oncogenic properties of PPM1D located within a breast cancer amplification epicenter at $17 \mathrm{q} 23$. Nature Genetics, 31, 133-134.

61. Momand, J., Jung, D., Wilczynski, S., \& Niland, J. (1998). The MDM2 gene amplification database. Nucleic Acids Research, 26, 3453-3459.

62. Rauta, J., Alarmo, E. L., Kauraniemi, P., Karhu, R., Kuukasjarvi, T., \& Kallioniemi, A. (2006). The serine-threonine protein phosphatase PPM1D is frequently activated through amplification in aggressive primary breast tumours. Breast Cancer Research and Treatment, 95, 257-263.

63. Yu, E., Ahn, Y. S., Jang, S. J., Kim, M. J., Yoon, H. S., Gong, G., et al. (2007). Overexpression of the wip1 gene abrogates the p38 MAPK/p53/Wip1 pathway and silences p16 expression in human breast cancers. Breast Cancer Research and Treatment, 101, 269-278.

64. Hirasawa, A., Saito-Ohara, F., Inoue, J., Aoki, D., Susumu, N., Yokoyama, T., et al. (2003). Association of 17q21-q24 gain in ovarian clear cell adenocarcinomas with poor prognosis and identification of PPM1D and APPBP2 as likely amplification targets. Clinical Cancer Research, 9, 1995-2004.

65. Saito-Ohara, F., Imoto, I., Inoue, J., Hosoi, H., Nakagawara, A., Sugimoto, T., et al. (2003). PPM1D is a potential target for $17 \mathrm{q}$ gain in neuroblastoma. Cancer Research, 63, 1876-1883.

66. Loukopoulos, P., Shibata, T., Katoh, H., Kokubu, A., Sakamoto, M., Yamazaki, K., et al. (2007). Genome-wide array-based comparative genomic hybridization analysis of pancreatic adeno- carcinoma: Identification of genetic indicators that predict patient outcome. Cancer Science, 98, 392-400.

67. Ehrbrecht, A., Muller, U., Wolter, M., Hoischen, A., Koch, A., Radlwimmer, B., et al. (2006). Comprehensive genomic analysis of desmoplastic medulloblastomas: Identification of novel amplified genes and separate evaluation of the different histological components. Journal of Pathology, 208, 554-563.

68. Mendrzyk, F., Radlwimmer, B., Joos, S., Kokocinski, F., Benner, A., Stange, D. E., et al. (2005). Genomic and protein expression profiling identifies CDK6 as novel independent prognostic marker in medulloblastoma. Journal of Clinical Oncology, 23, 8853-8862.

69. Castellino, C., De Bortoli, M., Moon S. H., Lu, X., Skapura, D. G., Lin, L. L., et al. (2007). Medulloblastomas overexpress the p53Inactivating oncogene Wip1/PPM1D. J. Neuro-Onc. (in press).

70. Demidov, O. N., Kek, C., Shreeram, S., Timofeev, O., Fornace, A. J., Appella, E., et al. (2007). The role of the MKK6/p38 MAPK pathway in Wip1-dependent regulation of ErbB2-driven mammary gland tumorigenesis. Oncogene, 26, 2502-2506.

71. Choi, J., Nannenga, B., Demidov, O. N., Bulavin, D. V., Cooney, A., Brayton, C., et al. (2002). Mice deficient for the wild-type p53induced phosphatase gene (Wip1) exhibit defects in reproductive organs, immune function, and cell cycle control. Molecular Cell Biology, 22, 1094-1105.

72. Belova, G. I., Demidov, O. N., Fornace Jr., A. J., \& Bulavin, D. V. (2005). Chemical inhibition of Wip1 phosphatase contributes to suppression of tumorigenesis. Cancer Biology and Therapy, 4, $1154-1158$.

73. Rayter, S., Elliott, R., Travers, J., Rowlands, M. G., Richardson, T. B., Boxall, K., et al. (2007). A chemical inhibitor of PPM1D that selectively kills cells overexpressing PPM1D. Oncogene (in press).

74. Proia, D. A., Nannenga, B. W., Donehower, L. A., \& Weigel, N. L. (2006). Dual roles for the phosphatase PPM1D in regulating progesterone receptor function. Journal of Biological Chemistry, $281,7089-7101$

75. Schito, M. L., Demidov, O. N., Saito, S., Ashwell, J. D., \& Appella, E. (2006). Wip1 phosphatase-deficient mice exhibit defective $\mathrm{T}$ cell maturation due to sustained p53 activation. Journal of Immunology, 176, 4818-4825. 